\title{
LA JUSTICIA EN DEBATE. EL CONSEJO DE LA MAGISTRATURA Y LA DEMOCRACIA MAYORITARIA
}

HUGO QUIROGA

Hugo Quiroga es Investigador de la Universidad Nacional de Rosario y Profesor en ésta y en la Universidad Nacional del Litoral.

e-mail: haquiroga@fibertel.com.ar

Todo conflicto nace y se desarrolla en un suelo de malestar. La disputa por el control del Consejo de la Magistratura, en Argentina, se ubica en las diferencias y controversias entre el poder político y el Poder Judicial en la cual se ponen al descubierto dos concepciones de democracia. El tema nos conduce a la esfera de la administración de justicia, y la justicia es algo que interesa a todos. Aunque los miembros de ambos poderes se necesitan mutuamente (los políticos que piden salvación y los jueces que pretenden ascender o no ser destituidos), la indispensable convivencia institucional no garantiza un funcionamiento sin fricciones, que muchas veces culmina en un conflicto de poderes.

Bajo ese telón de fondo, que hace al diseño constitucional de una república democrática, el debate actual en la política argentina posee tres pilares centrales íntimamente entrelazados: el control de la justicia, la búsqueda de impunidad del oficialismo y la continuidad del sistema de poder kirchnerista, más allá de las urnas. En esta estrategia, el Consejo de la Magistratura es una pieza esencial para dominar al Poder Judicial. No hay que olvidar, por encima de los vaivenes de la historia, que la administración de justicia constituye un poder del Estado. De ahí, las interminables rivalidades que mantiene el Poder Judicial con el Ejecutivo, cuando busca la regulación y limitación de los poderes públicos con la actuación del derecho.

Estos y otros temas serán los que contemplaremos en las páginas que siguen. Las preguntas centrales que organizan el trabajo giran en torno al rol de la justicia y la división de poderes en una república democrática, cuando, paradójicamente, 
vivimos en la era del dominio del Ejecutivo. En un primer apartado, nos centramos en conocer y entender las causas de las hostilidades entre los poderes Ejecutivo y Judicial y, al mismo tiempo, en señalar de qué modo se expresan en el actual escenario político democrático. En un segundo punto, nos ocupamos de describir las transformaciones institucionales, de base legal, con la creación del Consejo de la Magistratura, y las implicaciones que esos cambios tienen en el funcionamiento mismo de la democracia. El tercer apartado, se ocupa de analizar las acciones que se despliegan institucionalmente desde el Poder Ejecutivo para lograr controlar o dominar al Poder Judicial, utilizando el discurso público de la democratización de la justicia. El cuarto punto repasa las principales vertientes teóricas que nutren los diferentes modelos de Ejecutivo en algunos países, para detenerse en la descripción del modelo decisionista que caracteriza al sistema político argentino. Por último, las reflexiones finales recuperan los argumentos utilizados y los lineamientos teóricos centrales que ponen de relieve las consecuencias del decisionismo para nuestro sistema político, así como también exponen las tendencias a la judicialización de la política y la politización del control constitucional.

\section{CONTINUIDADES PROFUNDAS}

En una convivencia hostil entre los poderes Ejecutivo y Judicial, tan común en la Argentina, y en otros países, el interrogante central podría ser planteado de la siguiente forma: ¿̨uál es el trasfondo filosófico-político de esos enfrentamientos? En principio, lo que está en debate son dos concepciones de democracia y el modo de legitimación de las mismas.

Una, que proclama una concepción mayoritaria o plebiscitaria, basada en la soberanía popular, que reniega de los límites impuestos al Ejecutivo por la división de poderes y, específicamente, por las funciones de control del Poder Judicial. En esta visión, el jefe (del Estado o del gobierno) es la encarnación de la voluntad popular. El poder del número no hallaría trabas jurídicas. La democracia consistiría en la omnipotencia de la mayoría, en la idea de que la soberanía popular remueve y legitima cualquier obstáculo institucional. Desde esta perspectiva, la legitimidad popular es superior a la legitimidad constitucional. En este esquema resultan ilustrativas las palabras de la diputada Diana Conti: 
«Si tenemos una buena conductora y la gente la puede ratificar cada cuatro años. ¿Qué es más importante: la alternancia o que al país le vaya bien? Me parece horrible que el pueblo tuviera que votar a alguien por descarte, y que hubiera alguien que por impedimento constitucional no pudiera guiar los destinos del país, pese a haber mostrado una capacidad superior a cualquier otro dirigente» ${ }^{1}$.

La otra, que postula una democracia constitucional, se asienta en el principio de separación y equilibrio entre poderes. La igualdad de poderes es difícil, en los hechos no existe, siempre hay uno que domina a los otros. En general, lo que se manifiesta en la realidad es la superioridad del Ejecutivo. En un Estado de derecho democrático, el principio de la mayoría no es la única fuente de legitimidad, también lo es el orden constitucional. Más allá de la legitimidad de este debate (y aun inclinándonos por la segunda concepción), desde nuestra perspectiva es conveniente subrayar que los principios fundadores de la democracia son la libertad, la igualdad y la fraternidad. La democracia es el régimen político de la libertad y de la igualdad social.

En otros términos, se oponen dos concepciones de democracia, una populista o mayoritaria y otra liberal-republicana. Para la primera, la fuente de legitimidad del poder es exclusivamente el voto popular y, para la segunda, el procedimiento legal constitucional enmarca la decisión política que toma la autoridad pública legitimada por el resultado electoral. Aquí se localiza otra fuente de legitimidad del poder: la Constitución que es siempre el resultado de una convención democrática ${ }^{2}$. $\mathrm{O}$ bien, es un sistema de restricciones al poder del gobierno ${ }^{3}$. Son restricciones a la concentración del poder. La Constitución crea un proceso político, que en su sentido funcional significa garantizar el juego limpio por ser la «única base común a todos» ${ }^{4}$. No se trata, pues, de ser miembros de una misma comunidad étnica, sino de pertenecer a una nación de ciudadanos. En otras palabras, ciudadanos libres e iguales que forman parte de una comunidad política abierta a procesos de deliberación colectiva, más allá de cualquier concepto étnico de nación.

\footnotetext{
${ }^{1}$ La Nación, 18/11/2012.

2 Luigi Ferrajoli, Democracia y garantismo, Madrid, Edición de Miguel Carbonell, Trotta, 2008, p. 31.

${ }^{3}$ Carl J. Friedrich, Teoría y realidad de la organización constitucional democrática, México, Fondo de Cultura Económica, 1946, en especial caps. VII y VIII.

4 Jürgen Habermas, Mas allá del Estado nacional, Madrid, Trotta, 1997, p. 113.
} 
La Constitución democrática implica necesariamente separación de poderes, obviamente pueden existir constituciones sin esta exigencia, pero precisamente esa separación es lo que la distingue de una dictadura o de una revolución. Para Carl Schmitt la dictadura es la abolición de la separación de poderes ${ }^{5}$, noción que se distingue de otras como absolutismo despotismo o tiranía. La Declaración de los Derechos del Hombre y del Ciudadano del 26 de agosto de 1789, una de las primeras expresiones del constitucionalismo moderno, establece en su artículo 16: «Una sociedad en la que no está asegurada la garantía de los derechos ni determinada la separación de poderes, carece de Constitución» ${ }^{6}$. El profesor italiano Greppi se interroga en nuestros días si el principio de separación de poderes estará en condiciones de acompañar a la democracia en un momento de mutación como el que vivimos, cuando los poderes aparecen muy confusos. En su mirada, la alternativa a la creciente oposición entre los poderes reside en una «reinvención» del principio de separación ${ }^{7}$.

En la Argentina, cualquier limitación jurídica al Poder Ejecutivo enciende la furia del oficialismo actual, que pretende disciplinar a la justicia. El punto es que la democracia no flota en el aire, sino que se enmarca en el Estado de derecho. Son los límites legales al gobierno (que en la Argentina y en todos lados se confunde con el Ejecutivo). La cuestión sería: ¡cuál es el fundamento del Poder Judicial para intervenir de esa manera? Sin duda, la Constitución. La respuesta nos acerca a la idea de un poder constituyente, y su distinción de los poderes constituidos. El poder constituyente es un poder superior, soberano, que no es constituido por normas ni obedece a ninguna limitación jurídica. Los poderes constituidos sólo pueden ejercer facultades concedidas o aquellas otras que surgen implícitamente de las otorgadas en forma expresa ${ }^{8}$.

${ }^{5}$ Carl Schmitt, La dictadura, Madrid, Alianza Universidad, 1985, pp. 194-196.

${ }^{6}$ La Revolución francesa en sus textos, Madrid, Tecnos, 1989.

7 Andrea Greppi La democracia y su contrario. Representación, separación de poderes y opinión pública, Madrid, Trotta, 2012.

${ }^{8}$ En la opinión que ofrece Sièyes, en el contexto de la Revolución Francesa de 1789, se lee: «En cada parte la constitución no es obra del poder constituido, sino del poder constituyente. Ninguna suerte de poder delegado puede cambiar nada de las condiciones de la delegación», y agrega, la nación existe antes que nada, ella es el origen de todo, ella es la propia ley, Emmanuel Sièyes ¿Qué es el tercer Estado? y Ensayos sobre los privilegios, Barcelona, Oikos-tau, 1989, p. 107. 
En el período kirchnerista, sobre todo en el segundo mandato de Cristina Kirchner, el Ejecutivo y el Judicial han sido «enemigos potenciales», que han llevado adelante una tenaz lucha cotidiana, y en este campo de combate la escala de enfrentamiento no tiene precedentes, al menos, desde la restauración de la democracia en 1983. Por la carencia de reglas de sucesión del poder del oficialismo (de reglas internas para el recambio de Cristina Kirchner), el gobierno abrió con virulencia una contienda con la justicia para subordinarla, y tras ese objetivo modificó el sistema procesal penal -en el que los fiscales tendrán un papel fundamental en la investigación y los jueces un papel más limitado de garantizar el debido proceso y dictar sentencia-, con la intención de obtener garantías de impunidad frente a las extendidas denuncias de corrupción en el que está inmerso.

En esa dirección la Procuradora General de la Nación, Alejandra Gils Carbó, (alineada con la Presidenta) será ahora la responsable de la dirección de la política criminal del Estado nacional, que sale de la tradicional esfera del Congreso' ${ }^{9}$ La selección de los fiscales está sometida a un riguroso proceso de selección, de acuerdo a la reforma del Código. Pero como todavía no entró en vigencia, el gobierno, por intermedio de la Procuradora, aprovechó la situación para designar a fines del año 2014 a 16 fiscales subrogantes (esto es, sin concursos). Esta irregular situación dio lugar a varias presentaciones judiciales tanto de la Asociación de Magistrados como de otras instituciones. Dos fallos de la justicia dieron lugar a las medidas cautelares, los que fueron confirmados por la Sala de Feria de la Cámara en lo Contencioso Administrativo Federal el 30 de enero de 2014. La Cámara entendió que se trató de un «avasallamiento de su autonomía funcional (de la Procuradora) reconocida por el artículo 120 de la Constitución ${ }^{10}$. En consecuencia, los 16 fiscales subrogantes no pudieron asumir el 2 de febrero de 2015 tal como lo había previsto la Procuración. Nuevamente la colisión entre el Poder Ejecutivo y el Judicial, especialmente con los fiscales, sobrevino con la muerte política del

\footnotetext{
${ }^{9}$ El nuevo código introduce el sistema acusatorio en el que los fiscales tienen amplias facultades para dirigir la investigación. El eje del debate es el control de los fiscales, que dependerán de la Procuración General. El temor de la oposición reside en que los fiscales van a entender en causas vinculadas con la corrupción, bajo la órbita de Gils Carbó. En cambio, en un sistema dispositivo, el protagonismo lo tienen los jueces. En la Argentina se reemplazó un sistema mixto. El tema nos remite a un viejo conflicto sobre roles y funciones de fiscales y jueces en el proceso penal.

10 «La Cámara ratificó cautelar contra 16 fiscales», La Capital, 31/01/2015.
} 
fiscal Alberto Nisman, que puso en vilo a la sociedad argentina, por las graves consecuencias político-institucionales que se vislumbran.

En este caso, como en tantos otros, el conflicto de poderes se despliega ante el tribunal de la opinión pública. En general, se denomina opinión pública a esa «voz colectiva que, aun sin poder vinculante, siempre puede llegar más allá del control de los que están en el gobierno» ${ }^{11}$. Se trata de un "público» anónimo que mira, observa y juzga, a través de los medios masivos de comunicación, Internet, la telefonía móvil, en fin, las redes sociales, que ejercen un "poder negativo». En esa rivalidad, se busca la aprobación del tribunal de la opinión pública, aunque sea cambiante y efímera, para legitimar una decisión, dichos o comportamientos. $\mathrm{La}$ acción de juzgar realza el papel de «espectador» y anima un criterio de juicio, el de la imparcialidad, que es externo a la política ${ }^{12}$. El que juzga es un poder negativo o vigilante. En el estado actual de la democracia, junto al pueblo-elector se expande un pueblo-vigilante, un pueblo-veto y un pueblo-juez ${ }^{13}$.

\section{LA CREACIÓN DEL CONSEJO DE LA MAGISTRATURA}

El Consejo de la Magistratura fue instituido por la reforma constitucional de 1994 con el propósito de separar a la justicia de los objetivos transitorios de la acción de gobierno y con el fin de reafirmar el principio republicano de independencia del Poder Judicial. Se buscaba limitar las facultades discrecionales del Presidente para la designación de jueces. Así, la reforma modifica el sistema de designación de los jueces establecido por nuestra Constitución de 1853-1860, que siguió en su formulación general el diseño de la Constitución norteamericana, pero se distanció en la forma de concebir el poder presidencial, como se verá más adelante. Nuestra Constitución histórica sólo crea la Corte Suprema y deja librado al Congreso de la Nación la designación de los tribunales inferiores.

El Consejo de la Magistratura nace, pues, con la reforma de 1994. Su propuesta de creación fue incluida en el «Núcleo de Coincidencias Básicas» de la ley 24.309

${ }^{11}$ Bernard Manin, Principes du gouvernement représentatif, Paris, Calmann-Lévy, 1995, p. 222.

12 Sobre el particular, Nadia Urbinati, Democrazia in diretta. Le nuove sfide alla rappresentanza, Milano, Feltrinelli, 2013, p. 167.

${ }^{13}$ Véase Pierre Rosanvallon, en La contrademocracia. La política en la era de la desconfianza, Buenos Aires, Manantial, 2007. 
que declaró la necesidad de la reforma. El Núcleo de Coincidencias Básicas establecía los temas principales de la reforma sin que se pudieran introducir modificaciones. En virtud de la denominada «cláusula cerrojo», los Convencionales no podían discutir libremente el contenido y orientación de dicho Núcleo, debía ser aprobado o rechazado en su totalidad. Esto dio lugar a que algunos pusieran en duda el carácter soberano de la Convención Constituyente. Se imponía la obligación a votar en forma cerrada dicho Núcleo, que fue el resultado de lo acordado en el Pacto de Olivos, por Carlos Menem y Raúl Alfonsín.

Según el artículo 114 de la Constitución el Consejo tendrá a su cargo dos funciones centrales: la selección de los magistrados y la administración del Poder Judicial. Con esta segunda función es el responsable de ejecutar el presupuesto y dictar los reglamentos internos de la justicia, tarea que, hasta ese momento, era de exclusiva competencia de la Corte Suprema. Inmediatamente se abrió un campo de tensiones entre la Corte y el Consejo con respecto a las innovaciones introducidas en materia presupuestaria y facultades reglamentarias ${ }^{14}$.

La ley 24.937 de 1997, que regula el marco de funcionamiento del Consejo, limó las asperezas entre las dos instituciones aludidas al ubicar al Consejo como un órgano permanente del Poder Judicial y al integrar al Presidente de la Corte Suprema en su composición. El Consejo quedó compuesto con 19 miembros: el Presidente de la Corte, cuatro jueces del Poder Judicial de la Nación, elegidos por sistema D’Hont, ocho legisladores, cuatro por cada Cámara, dos de ellos corresponden al bloque de la mayoría, uno para la primera minoría y uno por la segunda minoría, un representante del Poder Ejecutivo y un abogado, elegido por sus pares.

El artículo 114 establece un principio fundamental que organiza y guía la nueva institución: el equilibrio entre sus representantes ${ }^{15}$. El Consejo será integrado

\footnotetext{
${ }^{14}$ Para un estudio sobre esas tensiones véase Ramón Enrique Trejo, «El Consejo de la Magistratura y la Corte Suprema de Justicia de la Nación», en: Pensar en Derecho, Facultad de Derecho, Universidad de Buenos Aires, XXIII, edición 234, 14/08/2014.

${ }^{15}$ El Comité de Derechos Humanos de la OEA en el Informe 2010, en la Observación 10, manifiesta, con respecto a la ley 26.080, lo que sigue: «El Comité observa con preocupación que, a pesar del principio contenido en el artículo 114 de la Constitución respecto del equilibrio que debe imperar en la composición del Consejo de la Magistratura, existe en el mismo una marcada representación de los órganos políticos allegados al Poder Ejecutivo, en detrimento de la representación de jueces y abogados (artículo 2 del Pacto)». Citado en Susana Cayuso, "Consejo de la Magistratura. Análisis constitucional de la Ley 26.855», en: Erreius on line, 2013 disponible en: http://www.erreius.com (último ingreso: 15/12/2014).
} 
periódicamente de modo que se procure un equilibrio entre la representación de los órganos políticos elegidos por el voto popular, los jueces de todas las instancias, los abogados de la matrícula federal y por personas del ámbito académico.

Transcurridos nueve años de funcionamiento se encontraron muchas falencias en el Consejo, que para muchos requería cambios a fin de ajustarse a los propósitos de los Constituyentes de 1994. Un cuerpo atravesado por conflictos y enfrentamientos que no tiene protagonistas ni alineamientos estables, pero que en todo caso reacciona corporativamente cuando debe disputar con la Corte Suprema atribuciones y competencias, merecía una revisión de su actuación.

Esta desfavorable situación alentó, entonces, la propuesta reformista del oficialismo presentada por la senadora Cristina Kirchner, cuando su marido era el Presidente de la Argentina. En febrero de 2006 se sancionó la ley 26.080 que modificó la integración del Consejo. De esta manera, se inicia una etapa en la que se rompe el equilibrio exigido por el artículo 114, se excluye al Presidente de la Corte de su composición, y se le resta autonomía al incorporar una mayor representación política. El nuevo Consejo quedó integrado por 13 miembros: tres jueces del Poder Judicial de la Nación, elegidos por sistema D’Hont, seis legisladores, tres por cada una de las Cámaras, de los cuales dos corresponden a la mayoría y uno a la primera minoría, dos representantes de los abogados de la matrícula federal, designados por el voto directo de los profesionales que posean esa matrícula (uno de ellos puede tener domicilio real en cualquier lugar del país) y un representante del Poder Ejecutivo.

La crítica principal a la nueva ley estuvo centrada en la ruptura del equilibrio reclamado por la Constitución, ya que otorgó mayoría de siete miembros a los representantes políticos (seis legisladores más el representante del Ejecutivo), y quedaron seis miembros distribuidos entre jueces, abogados y académicos. Por encima del valor de esta verdad, el problema es la incorrecta representación política de un organismo vinculado a la función judicial que requiere independencia institucional, competencia técnica y saber especializado. Por eso, la integración del Consejo se convirtió en una lucha política por su control. La reforma distorsiona aún más el sentido de este organismo cuando la representación política supera en número a la representación de carácter técnico-académica. El argumento reformista puso el acento en el comportamiento corporativo encarado por la antigua mayoría técnico-académica, que afectaba el normal desempeño del Consejo, además de 
aludir a la falta de celeridad y eficiencia en el funcionamiento, razones que, en la posición oficial, justificaban la modificación de su composición.

Los siete representantes políticos, de acuerdo al artículo 9 de la ley, forman quórum y pueden sesionar, y las decisiones se adoptan por la mayoría absoluta de los miembros presentes. La ley anula la posibilidad de debates y la toma de decisiones más transparentes al suprimir a las segundas minorías, y deja en clara supremacía a la representación política. Justamente, la mayor objeción proviene del carácter que reviste esa representación que tendrá un poder de veto ante las dos funciones principales del Consejo, la selección y remoción de los jueces, para lo que se necesita contar con los dos tercios de los miembros, número que no se logra si los representantes políticos no están de acuerdo.

En definitiva, la ley rompe el equilibrio imprescindible entre los poderes públicos, y se lesiona la ya maltrecha independencia institucional del Poder Judicial. Conforme a la nueva disposición, el oficialismo de turno estará en condiciones de decidir sobre la selección y remoción de los jueces. Desaparece o se atenúa la función de control de la justicia sobre el Ejecutivo y el Legislativo y, por el contrario, aumenta sobre ella el control del Poder Ejecutivo.

\section{«DEMOCRATIZAR LA JUSTICIA»}

Con la sanción de la ley 26.080 comienza otra época en el Consejo de la Magistratura, que se enmarca en las pretensiones (siempre presentes) del gobierno kirchnerista, por controlar al Poder Judicial. La intención del oficialismo, que tiene diversas vías de entrada, fue ocultada con su clásica retórica "progresista»: democratizar la justicia. La presidenta Cristina Kirchner presentó en el Museo del Bicentenario, a principios de abril de 2013, el proyecto de reforma judicial, que contemplaba seis iniciativas legales que enviaría al Congreso: la reforma del Consejo de la Magistratura, el ingreso democrático al Poder Judicial y al ministerio público fiscal, la publicidad de los actos del Poder Judicial, la creación de tres nuevas cámaras de casación, la publicidad y acceso directo a las declaraciones juradas de los funcionarios de los tres poderes del Estado, la regulación de medidas cautelares contra el Estado nacional y sus entes descentralizados ${ }^{16}$.

\footnotetext{
16 «Las seis leyes que propone el gobierno para democratizar la justicia» La Nación, 08/04/2013; «CFK presentó el proyecto para democratizar la justicia», Página 12, 08/04/2013.
} 
Todo un estilo y una estrategia para domesticar al Poder Judicial. Una de las vías principales de acceso es el avasallamiento del órgano que decide el destino y la suerte de los magistrados. Quien controla el Consejo de la Magistratura controla la principal herramienta de presión sobre la justicia. Tan sólo un ejemplo paradigmático (por fuera del juez Norberto Oyarbide que afronta once denuncias) para ilustrar la capacidad de bloqueo que le concedió la reforma de la ley 26.080 al oficialismo. El juez federal de Zárate-Campana, Federico Faggionatto Márquez (quien en un caso resonante resolvió citar a declarar al diputado Francisco de Narváez como sospechoso por la mafia de la efedrina en plena campaña electoral del 28 de junio, cuando enfrentaba a Néstor Kirchner en la provincia de Buenos Aires) había acumulado más de 30 acusaciones por graves irregularidades en sus funciones. Sin embargo, el doble voto de la presidenta de la comisión de acusación del Consejo, la diputada kirchnerista Diana Conti, evitó que fuera sometido a juicio político, a principios de octubre de 2009. Una semana más tarde, la ausencia inesperada de cinco miembros del oficialismo en la reunión plenaria del Consejo lo dejó sin protección. El Consejo lo suspendió por seis meses y resolvió someterlo a juicio político por mal desempeño en sus funciones ${ }^{17}$.

El avance por mejorar la calidad institucional de la justicia mediante el Consejo de la Magistratura sufrió un retroceso por la pérdida de autonomía. Entre las numerosas críticas que se le efectúan figuran las arbitrariedades en el manejo de los concursos de selección de jueces, que ha dado lugar a juicios planteados por quienes se sintieron perjudicados por la falta de transparencia en el procedimiento.

Sin embargo, la politización más extrema del Consejo de la Magistratura proviene de la sanción de la ley 26.855 de mayo de 2013. La retórica oficialista enarbola la bandera de la democratización de la justicia, y modifica la composición y la forma de designación de los integrantes del Consejo. El organismo se compone ahora por 19 miembros de los siguientes estamentos: tres jueces del Poder Judicial de la Nación elegidos mediante el sufragio universal, dos integrantes corresponden a la lista que resulte ganadora por simple mayoría, y uno a la que resulte en segundo lugar; tres representantes de los abogados de la matrícula federal, elegidos por

${ }^{17}$ Las profundas diferencias de posiciones entre Kunkel y Conti dividió al oficialismo, y dejó las puertas abiertas al juicio político. Kunkel mantiene, junto al radical Ernesto Sanz, una denuncia contra el juez Márquez desde el año 2007. Natalia Aguiar, «Kunkel y Conti discutieron fuerte en el Consejo de la Magistratura», Perfil, 17/10/2009. 
el pueblo por medio del sufragio universal -dos representantes para la lista que resulte ganadora por simple mayoría, y uno a la que resulte en segundo lugar-; seis representantes de los ámbitos académicos o científicos, de algunas de las disciplinas reconocidas oficialmente, elegidos por el pueblo de la Nación por medio del sufragio universal -cuatro representantes para la lista que resulte ganadora por simple mayoría, y dos a la que resulte en segundo lugar-; seis legisladores, tres por cada una de las Cámaras - de los cuales dos corresponden a la mayoría y uno a la minoría-; y un representante del oficialismo.

Con los cambios efectuados no sólo se transgrede el artículo 114 de la Constitución Nacional que, como vimos, exige el equilibrio entre los representantes de los diversos estamentos, sino que también se instaura el principio de la soberanía popular para la designación de todos los miembros del Consejo. Esta concepción mayoritaria de la democracia confunde a la democracia con la voluntad de la mayoría, y deja de lado la legitimidad constitucional. Al mismo tiempo, se contradice al no diferenciar el poder constituyente de los poderes constituidos, aunque, ciertamente, es en un tema complejo y controvertido. El contenido de la ley 26.855 infringe abiertamente la Constitución cuando no se respeta el diseño de una institución creada por Convención Constituyente. Las voces que se alzaron contra dicha ley fueron muchas y provinieron tanto del ámbito político como del judicial.

La decisión de la Corte Suprema de declarar inconstitucional los principales artículos de la ley de reforma del Consejo constituyó uno de los momentos cruciales del enfrentamiento entre los poderes Ejecutivo y Judicial, durante el segundo mandato de Cristina Kirchner. La Corte intervino por pedido del gobierno nacional que había solicitado un per saltum, luego del fallo de la jueza federal electoral María Servini de Cubría, que había declarado la inconstitucionalidad de ciertos artículos de la ley 26.855. La jueza de primera instancia se negó a oficializar las alianzas de los partidos que habían presentado candidatos para la elección de los consejeros de la Magistratura.

Luego de oír el dictamen de la Procuradora General de la Nacional, Alejandra Gils Carbó, la Corte declaró por amplia mayoría, a mediados de julio de 2013, la inconstitucionalidad de cuatro artículos de la ley 26.855, y del decreto presidencial 5777/2013. La sentencia resuelve: 
«I. Declarar la inconstitucionalidad de los artículos $2^{\circ}, 4^{\circ}, 18^{\circ}$ y $30^{\circ}$ de la ley 26.855 , y del decreto 577/13.

II. Declarar la inaplicabilidad de las modificaciones introducidas por dicha ley en relación con el quórum previsto en el artículo $7^{\circ}$, al régimen de mayorías y a la composición de las comisiones del Consejo, de conformidad con lo previsto en el artículo 29 de ley en cuestión.

III. Disponer que en los puntos regidos por las normas declaradas inconstitucionales e inaplicables, mantendrá su vigencia el régimen anterior previsto en las leyes 24.937 y sus modificatorias 24.939 y 26.080 .

IV. Dejar sin efecto la convocatoria a elecciones para los cargos de consejeros de la magistratura representantes de los jueces de todas las instancias, de los abogados de la matrícula federal y de otras personas del ámbito académico y científico establecida en los artículos $18^{\circ}$ y $30^{\circ}$ de la ley 26.855 y en los artículos $1^{\circ}, 2^{\circ}, 3^{\circ}$ y concordantes del decreto 577/13.

V. Aclarar que lo resuelto no implica afectación alguna al proceso electoral para los cargos de diputados y senadores nacionales establecido en el decreto $501 / 13 »^{18}$.

En su fundamentación la Corte reafirma,

«Por aplicación del principio de división de poderes ${ }^{19}$, que la interpretación de las leyes debe efectuarse sobre la base de que la declaración de inconstitucionalidad configura un acto de suma gravedad que debe ser considerado como última ratio del orden jurídico; sólo cabe acudir a ella cuando no existe otro modo de salvaguardar algún derecho o garantía amparado por la Constitución Nacional (Fallos: 249: 51, 288: 325; 306: 1597; 331: 2068; 333: 447)».

En síntesis, ¿cuáles son las consecuencias de la sentencia de la Corte con respecto a la ley 26.855? Se dispone la «inaplicabilidad» de la ley en todo lo que no resulte compatible con el fallo. Deja sin efecto la convocatoria a elecciones por voto popular de jueces, abogados y académicos, que debían participar de las internas abiertas de agosto y de las legislativas de octubre 2013. A la vez, retrotrae

18 Véase los textos completos del dictamen de la Procuración General de la Nación y de la Corte Suprema, disponible en https://microjuriscorp.wordpress.com (último ingreso: 15/12/2014).

${ }^{19}$ El destacado me pertenece. 
la composición del Consejo de 19 a 13 miembros, como existía con anterioridad a la reforma. Finalmente, las decisiones se tomarán, como antes, por mayoría de los dos tercios y no por la mitad más uno de los consejeros.

En sus fundamentos la Corte considera que la ley es violatoria del artículo 114 de la Constitución al establecer que los jueces, abogados y académicos, en representación de esos estamentos, se sometan al voto popular. A la vez, rompe el equilibrio entre la representación de los órganos políticos resultantes de la elección popular y de los que son designados en función de sus estamentos. El equilibrio apunta a que ningún sector tenga hegemonía sobre los demás. Igualmente la reforma obligaba a los jueces a intervenir en la lucha partidaria, resultando irrazonable que la boleta de los consejeros fueran adheridas a la de los legisladores nacionales. Resulta también poco sensato para la esfera judicial la prohibición de la formación de alianzas para competir en los comicios de consejeros, y que la ley estableciera el reconocimiento nacional en 18 distritos para poder presentar candidatos, cuando para la elección presidencial la exigencia se limita a cinco distritos.

Con la disidencia del juez Eduardo Zaffaroni, el máximo tribunal estimó que la Constitución busca equilibrar el poder para limitarlo, y que no se puede invocar la defensa de la voluntad popular para desconocer el orden jurídico. Recuerda que el Poder Judicial tiene la legitimidad que le concede la Constitución, y que no deriva de la elección popular. La función de los jueces es la de ejercer el control de constitucionalidad de las leyes, como hizo con las de obediencia debida y punto final. En suma, para la Corte la reforma del Consejo compromete la independencia institucional del Poder Judicial.

Zaffaroni fue el único juez que se pronunció a favor de la constitucionalidad de la ley, y coincidió con el dictamen de la procuradora Gils Carbó. En su argumentación repara que el artículo 114 de la Constitución Nacional no resulta concluyente, lo que "plantea un serio problema de conciencia y de autocontrol en el ejercicio de la jurisdicción constitucional». Ese artículo «navega» solo «con sus enormes carencias estructurales», con su «delegación de poder constituyente en el legislativo ordinario». En su opinión, la representación estamentaria, en la Constitución Nacional, es una excepción. En cambio, la regla republicana es la representación popular. No se le puede negar «al legislador el espacio para ensayar una estructura diferente ante la crisis, apelando por ello a una limitación procedente del derecho privado». Por esto, «no se puede sostener con éxito la existencia de una inconstitucionalidad manifiesta» en la cuestionada ley. Para Zaffaroni, en 
fin, lo que no contempló el poder constituyente queda en manos de los poderes constituidos, legislar por delegación ${ }^{20}$.

Mientras las oposiciones políticas celebraban el fallo de la Corte como un freno al avance del Ejecutivo sobre el Poder Judicial, y sobre las instituciones de la república, la reacción del gobierno no se hizo esperar ante su fracaso político. Las acusaciones fueron múltiples y de todo tenor. Se tildó a la Corte de corporativa, propia del medioevo, de asumir actitudes pre-democráticas, y de ser temerosa del voto popular. Pero las acusaciones de mayor confrontación estuvieron a cargo de la propia Presidenta en Rosario, el 20 de junio de 2013. Aunque con razón denunció que los jueces no pagan impuesto a las ganancias, ni hay presentación de declaraciones de bienes, sus palabras fueron temerarias por la descalificación del Poder Judicial en su conjunto. Cristina Kirchner acusó a la justicia de usar un poder de veto sobre el gobierno, y agregó que en el año 2015 le gustaría ser jueza para tener todos los privilegios correspondientes a esa función, y poder firmar cautelares que tumben las acciones de gobierno. Asimismo, culpó a los jueces por la inseguridad y el narcotráfico.

Lo que siguió después del fallo de la Corte fue un camino de «tira y afloja» entre los miembros más cercanos o más lejanos al gobierno, que en buena medida paraliza al Consejo, sobre todo en el momento en el que debían renovarse once de sus trece integrantes, en noviembre de 2014. En conclusión, por mayoría del oficialismo fue elegida presidenta del Consejo Gabriela Vázquez, y otro aliado del gobierno fue designado administrador general del Poder Judicial, Claudio Cholakian, quien reemplazó a Germán Krieger, una persona de confianza de la Corte Suprema ${ }^{21}$. No es un hecho menor, los miembros del Consejo duran cuatro años en sus funciones. Las ambiciones hegemónicas del Poder Ejecutivo hacen más difícil la subsistencia del principio de independencia e imparcialidad de los jueces.

\section{EL DOMINIO INCONTENIBLE DEL EJECUTIVO}

Según la Constitución de 1853 el Presidente era el que designaba al sistema judicial con el Acuerdo previo del Senado de la Nación. Este dispositivo institucional reforzaba las atribuciones de un Poder Ejecutivo ya vigoroso, que en su

\footnotetext{
20 www.csjn.gov.ar

${ }^{21}$ Paz Rodríguez Niell, «Fuerte avance del kirchnerismo en la Magistratura», La Nación, 21/11/2014.
} 
tiempo Alberdi reclamaba para conservar el orden y la paz. Decía textualmente la personalidad más influyente de la Constitución de 1853:

«QQué importa que las leyes sean brillantes si no han de ser respetadas?... ¿Teméis que el [E]jecutivo sea su principal infractor? (...) En tal caso no habría más que suprimirlo todo. ¿Pero podríais vivir sin gobierno? (...) Dad al poder [E]jecutivo todo el poder posible, pero dádselo por medio de una Constitución» ${ }^{22}$.

En palabras de Natalio Botana, «más allá de las declaraciones de derechos y garantías, de la competencia otorgada al Poder Legislativo y al Poder Judicial, y de la no reelección inmediata del presidente, la Constitución de Alberdi presenta la imagen de una agencia ejecutiva ${ }^{23}$. En efecto, el propio Alberdi, ya en su citado capítulo XXIV de las Bases, y en su texto Estudios de la Constitución Argentina de $1853^{24}$ (famoso también por su debate con Sarmiento), manifiesta que en relación con el Poder Ejecutivo de Norteamérica, el sistema argentino es completamente diferente. Se asemeja más al chileno por su fortaleza. El argentino es un «Ejecutivo fuerte» con atribuciones que no posee el de Norteamérica.

En las Bases, Alberdi señalaba:

«Chile ha hecho ver que entre la falta absoluta del gobierno y el gobierno dictatorial hay un gobierno regular posible; y es el de un presidente constitucional que pueda asumir facultades de un rey, en el instante que la anarquía le desobedece como presidente republicano» ${ }^{25}$.

He destacado de este párrafo la distinción entre "presidente constitucional» y "presidente republicano». Ante casos excepcionales (la anarquía, por ejemplo), el primero puede asumir facultades extraordinarias (de un rey dice Alberdi) con el fin de obtener la obediencia que se le niega al presidente republicano.

22 Juan Bautista, Alberdi, Bases y puntos de partida para la organización política de la República Argentina, Buenos Aires, Editorial Lancelot, 1994, p. 172 (el subrayado me pertenece).

${ }^{23}$ Natalio Botana, «Un debate fundador. Estudio preliminar», en: Sarmiento-Alberdi. Constitución y política, Buenos Aires, Hydra, 2012.

24 Juan Bautista, Alberdi, en: Sarmiento-Alberdi. Constitución y política, op. cit., cap. V.

${ }^{25}$ ĺdem, p. 171 (el subrayado me pertenece). 
El tema viene a cuento porque cuando se establece una república uno de los problemas más complejos a resolver es el papel del Poder Ejecutivo. ¿Cuáles son sus atribuciones?, ¿cómo es la relación con los otros dos poderes? En un libro de 1906 dedicado exclusivamente a analizar el rol del Ejecutivo, Barthélemy ${ }^{26}$ considera tomando en cuenta las constituciones de Europa y de América- que hay diferentes concepciones del Poder Ejecutivo. Cuando el Ejecutivo no es representante, ni órgano directo, ni gobernante, se halla completamente sometido a la legislatura. A este tipo se lo califica como Ejecutivo parlamentario. El Ejecutivo es un «agente del Legislativo». Si, al contrario, el Ejecutivo es planeado como un representante del pueblo, un órgano directo, un gobernante de la Nación, se convierte en independiente del Legislativo, pasa a ser un «Ejecutivo gobernante», un «Ejecutivo representante» que ejerce con eficacia los poderes que le confiere la Constitución.

En América Latina, según interpreta Barthélemy, todas las repúblicas le conceden el ejercicio del Poder Ejecutivo a un titular único, cuyas atribuciones son las mismas que las del Presidente de los Estados Unidos. El autor francés, más allá de lo que hemos observado del caso argentino, le otorga al Ejecutivo vitales atribuciones, un lugar considerable en el esquema gubernamental, debido al temperamento de la población, a su tradición católica, a su inclinación por la autoridad antes que por la libertad. Al matizar su razonamiento entiende que si bien las repúblicas de América latina han adoptado las instituciones republicanas, al tener en cuenta el medio en que actúan, el gobierno presidencial sobreviene en una «dictadura presidencial». "Ellos vacilan entre un desorden que es como la anarquía y un poder personal que se asemeja a una dictadura ${ }^{27}$.

Finalmente, Barthélemy deja en claro, con los matices de los diferentes sistemas de gobierno, que el rol del Ejecutivo no es el de «ejecutar», sino que consiste en ejercer la representación del Estado con respecto a todos, tanto en el interior como en el exterior, así como también el de desempeñar la gestión y administración de los asuntos públicos. El Ejecutivo tiene la función de representación de la unidad del Estado, calificada lato sensu de función de «majestad $»^{28}$.

${ }^{26}$ Joseph Barthélemy, Le Rôle du Pouvoir Exécutif dans les Républiques Modernes, Giard et Briéres, Paris, Libraires-Editeurs, 1906. Jurista y político francés, fue ministro de Justicia en el régimen de Vichy entre 1941 y 1943.

27 Ídem, p. 201.

${ }^{28}$ Ídem, pp. 10-11 
La idea de democracia plebiscitaria pasa a ocupar un primer plano en la reflexión de Max Weber hacia fines de 1918, y con más énfasis en 1919, y cree que esa es la mejor fórmula para la reorganización político-institucional de la Alemania de post-guerra. En el esquema de un sistema presidencial plebiscitario, Weber reclama fervorosamente la elección popular del Presidente del Reich ${ }^{29}$, lo que facilitaría la mejor selección de los líderes políticos, y le otorgaría una legitimidad por derecho propio frente al parlamento. El Presidente, apoyado por la confianza de las masas y con amplias atribuciones, puede garantizar con su carisma la unidad de la Nación, y puede intervenir en el caso de una crisis parlamentaria. Se gestaría una nueva relación entre el líder y las masas, porque la desorganización de las mismas, dominadas exclusivamente por los factores emocionales, puede dar lugar a la democracia de la calle.

El dominio del Ejecutivo no dejó de aumentar. En la actualidad, tiene una gran libertad. El predominio del Ejecutivo sobre los otros poderes, el Legislativo y el Judicial, es notorio en los regímenes presidencialistas, parlamentarios o semipresidencialistas. El Ejecutivo desempeña la dirección política del Estado, y la función -siempre complicada- de los otros poderes es saber cómo controlarlo, para evitar o disminuir las arbitrariedades y abusos de poder. En palabras de Sergio Fabbrini, la internalización y la europeización de las democracias aumentaron la influencia de la política exterior en las relaciones institucionales internas, y ello, a su turno, promovió la preeminencia decisional de los Ejecutivos y de los líderes en detrimento de los Legislativos y de las oposiciones. En síntesis, el Poder Ejecutivo se ha vuelto, sin duda, el poder central en las democracias modernas ${ }^{30}$.

${ }^{29}$ Esta cuestión Weber la plantea inicialmente en un conjunto de artículos periodísticos publicados entre el 22 de noviembre y el 5 de diciembre de 1918, véase "La futura forma institucional de Alemania», en: Max Weber, Escritos políticos. II, México, Folio Ediciones, 1982. En el mismo volumen se pueden encontrar textos de principios de 1919, con la misma orientación, y ampliados con otros temas «El presidente del Reich», «La política como vocación».

${ }^{30}$ Sergio Fabbrini, El ascenso del Príncipe democrático. Quién gobierna y cómo se gobiernan las democracias, Buenos Aires, Fondo de Cultura Económica, 2009, p. 231. 
La gran preocupación de nuestra democracia republicana de hoy es, como antes, la limitación del poder. El decisionismo democrático ${ }^{31}$ ensancha la esfera del Ejecutivo, y corre los límites de la institucionalización. Es un modo no republicano de ejercicio del poder. Sin los mecanismos de representación funcionando con plenitud y eficacia (Ejecutivo, Congreso, partidos) y sin una clara separación de poderes, no se puede sostener una esfera pública democrática. Una vez más, el decisionismo democrático, en tanto práctica de gobierno, cambia la base del poder público, no respeta el reparto constitucional del poder, impone el dominio del Ejecutivo, atenúa el Estado de derecho y provoca una erosión de todo poder de contralor. La lógica decisionista, la voluntad política del Presidente, se impone sobre la lógica deliberativa, y sobre la independencia de los jueces, que es el nervio del Poder Judicial.

La embestida del Poder Ejecutivo contra el Judicial durante el período kirchnerista provocó situaciones de mucha tensión. Quizá la de mayor intensidad fue la generada por la muerte política del fiscal Alberto Nisman. Esa pérdida de carácter público es el rasgo que la diferencia de una muerte privada, íntima. Las causas dudosas que rodean la muerte del fiscal que había denunciado por encubrimiento a la presidenta de la Nación, al canciller Timerman y estrechos colaboradores, revela una crisis institucional inusitada, al menos, desde 1983. Evidencia la gravedad de lo que acontece en las instituciones y en la sociedad argentina. Uno de los tres poderes del sistema republicano fue atacado para impedir el cumplimiento de su función esencial: impartir justicia. Es un golpe a la división de poderes, al corazón de la democracia. La reacción de segmentos importantes de la sociedad fue inmediata, y los fiscales, con el apoyo de algunos jueces, convocaron a una concentración en homenaje de Alberto Nisman, el 18 de febrero de 2015. La respuesta del oficialismo fue amenazar al Poder Judicial y acusar de que se organizaba un "golpe blando», o un "golpe judicial», de una justicia que se había politizado. En pocas palabras, se ha producido para el gobierno la contaminación política de la justicia. La judicialización de la política es una vieja polémica que se renueva constantemente.

${ }^{31}$ He trabajado este concepto en La Argentina en emergencia permanente, Buenos Aires, Edhasa, 2005, La República desolada. Los cambios políticos de la Argentina (2001-2009), Buenos Aires, Edhasa, 2010, y en «Parecidos de familia. La democracia delegativa y el decisionismo democrático», en: Guillermo O'Donnell, Osvaldo lazzetta, Hugo Quiroga (coordinadores), Democracia Delegativa, Buenos Aires, Prometeo, 2011. 


\section{JUDICIALIZACIÓN DE LA POLÍTICA Y POLITIZACIÓN DEL CONTROL CONSTITUCIONAL}

El debate sobre la independencia del Poder Judicial es una cuestión permanente, presente en todos y cada uno de los momentos de la historia argentina. La mayoría de las veces no deja de ser un discurso retórico. De ahí, la pregunta clave: ¡cuál es la función de la Corte Suprema y de los tribunales inferiores? Ejercer el control de constitucionalidad de las leyes y de los actos de gobierno de los otros poderes. No obstante, esta función no les permite a los tribunales argentinos declarar la nulidad de las leyes consideradas inconstitucionales sino tan sólo evitar su aplicación. En nuestro sistema democrático, le cabe al Poder Judicial el control de legalidad sobre los «actos inválidos» y los «actos ilícitos» -como bien sostiene el filósofo del derecho italiano Luigi Ferrajoli ${ }^{32}$-, cometidos por los otros poderes públicos, el Ejecutivo y el Legislativo. Los jueces son la garantía de legalidad de los poderes públicos.

En consecuencia, carece de sentido la acusación de judicialización de la política realizada por el gobierno ante determinados casos. La justicia interviene para indagar sobre las denuncias de violaciones del derecho, es decir, sobre los actos inválidos o los actos ilícitos que se hubieran cometido. La acusación oficial debe ser invertida. Precisamente, la justicia (o ciertos jueces) interviene correctamente porque deja de estar politizada y comienza a cumplir con su deber de control de las ilegalidades de los otros poderes. Los jueces, si son independientes, no hacen política desde el momento en que cumplen con la defensa de la legalidad.

En nuestro país, los razonamientos en torno a este tema están invertidos, y se malinterpreta la judicialización de la política. La politización de la justicia fue la tendencia imperante en la Argentina, en el sentido de que cada gobierno, civil o militar, moldeaba a la Corte Suprema a su imagen y semejanza para reunir avales jurídicos indispensables para las medidas del gobierno. Obviamente, esa justicia politizada no podía ejercer el control de legalidad del poder. En rigor, ese control es una función política del Poder Judicial, pero sin un sentido partidista.

La judicialización de la política es un fenómeno mundial. Sobre ese punto, la mirada debería ser otra. En efecto, hay un nuevo rol de la justicia, más preponderante, no sólo en el campo político sino también en el económico-social y

32 Luigi Ferrajoli, Democracia y garantismo, op. cit., p. 215. 
cultural. En ese sentido, los jueces controlan la discrecionalidad del poder político y hacen respetar los derechos fundamentales establecidos en la Constitución. Los gobernantes no responden únicamente ante los electores, sino también frente a los jueces cuando ejercen el control de legalidad. El temor comprensible de los gobernantes es que se caiga en el extremo del «gobierno de los jueces», hipótesis muy poco plausible para la tradición política hiperpresidencialista argentina.

Una cosa es que la Corte, o el Poder Judicial, sea un instrumento del poder político y otra es el cumplimiento de una función de naturaleza política, debido a su rol de control de legalidad de los poderes. Aunque ciertas decisiones jurídicas tengan un carácter político, por la naturaleza de la materia en discusión, ello no indica que la Corte realice de manera automática una acción política partidista con sus pronunciamientos. Al tener la atribución de declarar la inconstitucionalidad de las leyes y de los actos de gobierno, se constituye en el órgano de control más importante del Estado de derecho democrático, por ende, sus sentencias tienen un significado político. Su palabra final, reviste consecuencias políticas, cuando expone «objeciones contramayoritarias» sin ser elegido por las urnas ${ }^{33}$.

El problema reside en que el poder político, en una concepción decisionista de la democracia, no acepta la existencia de otro poder que pueda controlarlo. La dimensión conflictiva no se puede eliminar, porque lo que está en juego es la distribución del poder, pero, a la vez, no se puede dejar de reconocer que el principio de legitimidad es el cimiento del poder conforme a la ley. La contienda se explica porque el Estado es el palacio que alberga el poder, con sus tres divisiones. Complejizando la idea de legitimidad jurídica, Hauriou sostiene que si bien no es «el poder el que nace de la ley, sino, al contrario, es la ley la que nace del poder, en cuanto el poder existe antes que todo; seguidamente, él mismo se siente obligado a someterse a esas leyes...» ${ }^{34}$. En fin, la historia es lucha de poderes, el poder tiene vida propia, el conflicto es inevitable ${ }^{35}$. En verdad, hay una conexión

${ }^{33}$ En este amplio debate sobre la justicia se puede consultar la obra de Roberto Gargarella, La justicia frente al gobierno. Sobre el carácter contramayoritario del poder judicial, Buenos Aires, Ariel, 1996. ${ }^{34}$ Maurice Hauriou, Principios de derecho público y constitucional, Granada, Editorial Comares, [1910] 2003, p. 218, cita 33.

${ }^{35}$ Véase, Bertrand De Jouvenel, Sobre el poder. Historia natural de su crecimiento, Madrid, Unión Editorial, 1998. 
estrecha entre poder y derecho. El derecho halla su fundamento en el poder, pero, al mismo tiempo, el poder necesita del derecho como condición imprescindible para instituir tanto un orden político como un orden jurídico.

El Consejo de la Magistratura, una institución beneficiosa para fortalecer la división de poderes, al cambiar el sistema de designación de los jueces, fue criticada severamente por el kirchnerismo por suscitar una tendencia "corporativa» en el Poder Judicial. En su vocación hegemónica, el gobierno presentó como alternativa que los jueces fueran designados por la mayoría parlamentaria, por el voto popular, en definitiva, por el Poder Ejecutivo. Se lo concibió como un medio de presión política sobre los jueces. En los hechos, el Poder Judicial no es independiente y no puede desarrollar en total libertad su función de contrapesar al Poder Ejecutivo para limitar sus eventuales excesos. No obstante, muchos jueces, y la Corte Suprema, han actuado con independencia, y han expresado su malestar por las injerencias sufridas. La reacción de los fiscales convocando a una concentración para honrar la memoria de Alberto Nisman puede significar un avance cualitativo en la disputa (eterna) entre dos poderes del Estado, y un cambio en la cultura política de los gobernantes y de los jueces en busca de un nuevo modelo judicial libre (de prebendas y temores), exento de manipulaciones y democrático. La verdad se encuentra en la Constitución, y si no es así será conveniente reformarla, pero no le echemos toda la culpa a la Carta Magna. «He leído y releído no sé cuántas veces nuestra Constitución (y tantas otras); pero nunca logré desentrañar en esas fórmulas el secreto del buen gobierno» ${ }^{36}$. Naturalmente, la vigencia y solidez de un orden jurídico depende del compromiso de los poderes públicos, de los ciudadanos y de los múltiples actores (incluidas las redes sociales) con el Estado de derecho democrático.

La Argentina necesita de un modelo judicial democrático, que deje actuar libremente a los jueces, sin intervención de los órganos ejecutivos y poderes económicos que pretenden torcer o influenciar en sus resoluciones. Los jueces no pueden vivir asfixiados entre la politización y el retraso inadmisible en la administración de justicia por el congestionamiento de las causas sin resolver.

36 "La Constitución no tiene la culpa», en: Norberto Bobbio, Las ideologías y el poder en crisis, Barcelona, Ariel, 1988. 
Una democracia desarticulada es un orden político sin raíces institucionales sólidas y duraderas, carente de una ciudadanía comprometida y «creyente» de los postulados democráticos. No es ésta la situación de la Argentina actual, pero está a medio camino. Es una democracia débilmente estructurada, más allá de que mantenga firme un sistema de votación. La democracia, como forma de organizar el ejercicio público del poder, sufre el impacto de la superioridad del Ejecutivo sobre el Legislativo y el Judicial. Más allá del respeto que nuestra historia política haya tenido o no a la Carta Magna, la Constitución tiene siempre la última palabra.

\section{Registro bibliográfico}

QUIROGA, HUGO

«La justicia en debate. El Consejo de la Magistratura y la democracia mayoritaria», en: ESTUDIOS SOCIALES, revista universitaria semestral, año XXV, no 48, Santa Fe, Argentina, Universidad Nacional del Litoral, primer semestre de 2015, pp. 147-168.
Recibido: 28 / 02 / 2014

Aprobado: 20 / 03 / 2015 